\title{
Perception and attitude of religious leaders and outpatients in Dhaka, Bangladesh with regard to Ayurvedic medicine
}

\author{
Yoshitoku Yoshida ${ }^{1}$, Yasuko Yoshida ${ }^{2}$, Md. Abdul Alim ${ }^{3}$, Zakia Alam ${ }^{3}$, Mohammad Asaduzzaman ${ }^{4}$ and Manikdrs Shahabuddin ${ }^{4}$ \\ ${ }^{1}$ Faculty of Nursing, Shubun University, Japan \\ ${ }^{2}$ Graduate School of Pharmaceutical Sciences, Nagoya City University, Japan \\ ${ }^{3}$ Institute of Public Health Nutrition, Bangladesh \\ ${ }^{4}$ National Tuberculosis Control Program, Directorate General of Health Services, Leprosy Hospital Compound, Bangladesh
}

\begin{abstract}
Objectives: Because of limited medical and financial resources, the use of complementary and alternative medicine (CAM) should be markedly expanded in Bangladesh. From the viewpoint of increasing the use of Ayurvedic medicine (AM) including herbal medicine (HM) more vigorously, new and important recommendations need to be obtained through data comparison among Muslim religious leaders (MRLs), AM outpatients (AMOPTs), and orthodox medicine outpatients (OMOPTs). Therefore, the aim of this study was to confirm the perception and attitude of MRLs, AMOPTs, and OMOPTs toward AM in Dhaka, Bangladesh.
\end{abstract}

Method: This study was conducted from February to June 2015 by trained staff members using a structured questionnaire. The interview respondents were 150 MRLs, 202 AMOPTs, and 150 OMOPTs in Dhaka, Bangladesh.

Results: More than 85\% AMOPTs and MRLs had a person who helped him/her to use AM; however, only 10.3\% OMOPTs had such a person. OMOPTs were skeptical but had no one to help them use AM and suggests that OMOPTs were not familiar with using AM. In terms of attitudes, OMOPTs harbored more skepticism than the other two groups.

Conclusions: If OMOPTs had more chances of becoming familiar with AM through someone helping them with its use, then they would use AM more. In addition, to increase the use of AM, appropriate information on its efficacy and safety should be provided to the general public to avoid skepticism.

\section{Introduction}

To enact the concept of the Declaration of Alma-Ata in 1978 [1] the World Health Organization (WHO) prepared the WHO Traditional Medicine Strategy 2014-2023 [2]. The main purpose of this strategy is to help member states promote the safe and effective use of traditional medicine (TM).

In Japan, herbal medicine (HM) is used as Kampo, which is covered by universal health insurance [3-5]. Furthermore, to provide evidence-based medicine to patients, a lot of rigorous studies have been conducted on the efficacy and safety of Kampo [6-13].

In Bangladesh, economic growth has remarkably progressed; however, the central government is struggling with difficulties related to public health issues [14-21]. In terms of the resource limitations of healthcare and economical activities, the use of complementary and alternative medicine (CAM) needs to be considerably increased in Bangladesh.

In Bangladesh, a national policy on TM and CAM was issued in 1995. However, national laws and regulations are currently in the development stage. Although a national program was introduced in 1998, national research institutes on TM, CAM, or Ayurvedic medicine (AM) including HM have not yet been established. Whereas HMs are regulated as prescription and over-the-counter drugs, national herbal monographs have not yet been developed. The Drug Administration is in charge of ensuring the implementation of pharmacopeias and monographs, good manufacturing practice (GMP) rules for conventional pharmaceuticals, and special GMP rules; however, no detailed information about specific mechanisms is available. A registration system for HMs exists; however, the number of registered products is unavailable. A post-marketing surveillance system is currently under development. The Ministry of Health and Family Welfare of Bangladesh adopts various countermeasures to promote the health and welfare of the country.

Therefore, in 2011, a study on the perceptions of Muslim religious leaders (MRLs) and citizens in Bangladesh regarding AM was performed by a team involving two of the current authors [22,23]. We chose not only citizens but also MRLs as respondents because MRLs influence the lives of citizens, including the use of AM. The results showed that MRLs had an adequate perception, satisfaction, and a very positive attitude toward HM and regarded the mass media as having a significant contribution toward its promotion. However, the citizens believed that scientifically sound information on AM should be promptly collected to eliminate the skepticism of younger citizens

Correspondence to: Yoshitoku Yoshida, Faculty of Nursing, Shubun University, 6 Nikko-cho, Ichinomiya City, Aichi Prefecture, 491-0938, Japan, Tel and Fax: +81-586-45-2101; E-mail: yoshida.yo@shubun.ac.jp

Key words: ayurvedic medicine, perception, Bangladesh, religious leader, outpatient

Received: October 19, 2016; Accepted: October 25, 2016; Published: October 31,2016 
in Dhaka. Because of limited medical and financial resources, the use of CAM needs to markedly increase in Bangladesh. The latter studies were conducted in Bangladesh in 2011; however, at that time, we did not collect data from AM outpatients (AMOPTs) or orthodox medicine outpatients (OMOPTs). From the viewpoint of further increasing the use of AM, other important and new recommendations might be obtained through data comparison among MRLs, AMOPTs, and OMOPTs.

Therefore, the aim of this study was to confirm the perception and attitude of MRLs, AMOPTs, and OMOPTs to AM in Dhaka, Bangladesh.

\section{Materials and methods}

This study was conducted in Dhaka, Bangladesh from February to June 2015 by face-to-face interviews with trained staff members using a structured questionnaire. The four data-collecting staff members had been trained in collecting data from the respondents. Their interviewing skills were also assessed prior to conducting the interviews.

The interview respondents included 150 MRLs, 202 AMOPTs, and 150 OMOPTs who were randomly selected and recruited by the trained staff members of the Bangladeshi research team. In terms of recruit of AMOPTs and OMOPTs, the trained staff members of the Bangladeshi research team visited a hospital or an office of practitioner and randomly picked up 202 AMOPTs, and 150 OMOPTs who visited that place. There were no exclusion criteria in this study. The subjects were informed that they were free not to respond to any question that they were not comfortable answering. Their anonymity was preserved. Verbal informed consent was obtained from every participant prior to the interview.

The questionnaire was translated from English into Bengali and was modified for the respondents' understanding before data collection in the field. It was then back-translated to English. The respondents responded to situations and perceptions regarding AM use and satisfaction from AM use. For questions on attitudes toward AM use, a 5 -point Likert scale ranging from $1=$ "Strongly disagree" to $5=$ "Strongly agree" was applied.

Raw data were sent to Nagoya University and analyzed using SPSS version 2.0. $\chi^{2}$-test and Kruskal-Wallis test were applied.

Prior to data collection, the study protocol was approved on October 23, 2014 by the Ethics Committee of the Graduate School of Medicine, Nagoya University (approval number: 2014-0208).

\section{Results}

Table 1 shows the demographics of the respondents. We obtained responses from 150 MRLs, 202 AMOPTs, and 150 OMOPTs. In terms of age, 52.7\% MRLs were 35-54 years old, 48.5\% AMOPs were 15-54 years old, and 54.7\% OMOPTs were $35-54$ years old. With regard to gender, 95.3\% MRLs, 58.6\% AMOPTs, and 78.0\% OMOPTs were male. In terms of marital status, $80.0 \%$ MRLs, $75.1 \%$ AMOPTs, and $78.0 \%$ OMOPTs were married. With regard to the amount of use of AM per year, $47.9 \%$ MRLs marked 5 to 6 times, $49.5 \%$ AMOPTs marked 3 to 4 times, and $45.0 \%$ OMOPTs marked 0 times. In terms of the amount of use of OM per year, 38.7\% MRLs marked 5 to 6 times, $49.2 \%$ AMOPTs marked 1 to 2 times, and 57.9\% OMOPTs marked 5 to 6 times. These five items had statistically significant differences. Thus, fraction of young respondents was greater for AMOPTs relative to MRLs and OMOPTs. It was noted that the frequency of the use of AM was higher for MRLs than AMOPTs which was in turn higher than OMOPTs.

With regard to education, 31.3\% AMOPTs and 55.0\% OMOPTs had 11 or more years of education. In terms of occupation, $30.7 \%$ AMOPTs worked in business, and 34.5\% OMOPTs worked in service. These two items had statistically significant differences. With regard to monthly income, $45.1 \%$ AMOPTs earned 7000 Taka or less, and 41.0\% earned 7000-150000 Taka. On the other hand, $47.5 \%$ OMOPTs earned 7000-150000 Taka, and 42.6\% earned 7000 Taka or less. There was no statistical significance, but there seemed to be some trend that higher income for OMOPTs relative to AMOPTs. In terms of religion, 95.3\% AMOPTs were Muslim, and 4.2\% were Hindu. On the other hand, $88.4 \%$ OMOPTs were Muslim, and $9.5 \%$ were Hindu. There was a statistically significant difference.

Table 2 shows the perception toward AM use in Dhaka, Bangladesh. In terms of the mode of the effect of AM, $62.1 \%$ MRLs believed that it was for the prevention of disease. On the other hand, 37.9\% AMOPTs believed that it was for the treatment of disease, and $37.4 \%$ believed that it was for health promotion. Furthermore, 58.5\% OMOPTs believed that it was for health promotion. Moreover, 64.8\% MRLs believed that AM worked via disease eradication, and $26.2 \%$ believed that AM worked through relaxation. On the other hand, $72.8 \%$ AMOPTs believed that AM worked via disease eradication, and $25.2 \%$ believed that AM improved the body's defenses. In addition, 30.9\% OMOPTs believed that AM worked through improving the body's defenses, and 38.3\% believed that AM worked via disease eradication. There were statistically significant differences. Regarding the effectiveness of AM in males and females, 95.9\% MRLs, 97.4\% AMOPTs, and 96.6\% OMOPTs believed that AM was effective in both males and females. There was a statistically significant difference. Thus, these results demonstrate a marked difference in perception of significance of AM along the three groups.

With regard to satisfaction of AM use, as shown in Table 3, 89.9\% MRLs, 99.5\% AMOPTs, and 60.0\% OMOPTs reported benefit from AM. In contrast, $4.1 \%$ MRLs, $62.2 \%$ AMOPTs, and 0.0\% OMOPTs reported harm from AM. Furthermore, 4.1\% MRLs, 36.7\% AMOPTs, and $8.9 \%$ OMOPTs were very satisfied with AM, and 93.2\% MRLs, 62.7\% AMOPTs, and $88.4 \%$ OMOPTs were satisfied with AM. Moreover, 93.9\% MRLs, 99.0\% AMOPTs, and 57.5\% OMOPTs said that they would recommend AM to others. Of note, $88.6 \%$ MRLs, 85.6\% AMOPTs, and 10.3\% OMOPTs had a person who helped them use AM, whereas, $70.9 \%$ MRLs, $100.0 \%$ AMOPTs, and 78.5\% OMOPTs believed that the government should take more initiative in promoting AM. Furthermore, $87.4 \%$ MRLs, 98.9\% AMOPTs, and 6.4\% OMOPTs believed that if the treatment cost was the same, they would choose AM. These differences were statistically significant. Overall, this section represents greater degrees of satisfaction of the MRLs and AMOPTs compared to OMOPTs.

Regarding the attitudes toward AM, as shown in Table 4, 73.5\% MRLs agreed, and $17.7 \%$ had not decided whether the AM provider gave good information on maintaining a healthy lifestyle. Furthermore, $70.1 \%$ AMOPTs strongly agreed, and $27.9 \%$ agreed that the AM provider gave good information on maintaining a healthy lifestyle. Moreover, $56.0 \%$ OMOPTs had not decided, and $42.7 \%$ agreed that the AM provider gave good information on maintaining a healthy lifestyle. In addition, 74.5\% MRLs agreed that HM had fewer side effects. Moreover, $71.7 \%$ AMOPTs strongly agreed that HM had fewer side effects. Regarding side effects, $69.3 \%$ OMOPTs agreed that HM had fewer side effects. Furthermore, 77.2\% MRLs agreed, and $13.4 \%$ 
Table 1. Demographic data of respondentsin Dhaka, Bangladesh.

\begin{tabular}{|c|c|c|c|c|c|c|c|c|c|c|}
\hline & & \multicolumn{8}{|c|}{ Sex } & \multirow{3}{*}{ Testa } \\
\hline & & \multicolumn{2}{|c|}{ Religious leaders } & \multicolumn{2}{|c|}{$\begin{array}{c}\text { Outpatients of Ayurvedic } \\
\text { medicine }\end{array}$} & \multicolumn{2}{|c|}{$\begin{array}{c}\text { Outpatients of Orthodox } \\
\text { medicine }\end{array}$} & \multicolumn{2}{|c|}{ Total } & \\
\hline & & $\mathrm{n}$ & $\%$ & $\mathrm{n}$ & $\%$ & $\mathrm{n}$ & $\%$ & $\mathrm{n}$ & $\%$ & \\
\hline \multirow{4}{*}{ Age } & $15-34$ & 52 & $34.7 \%$ & 98 & $48.5 \%$ & 40 & $26.7 \%$ & 190 & $37.8 \%$ & \multirow[t]{3}{*}{$* *$} \\
\hline & $35-54$ & 79 & $52.7 \%$ & 73 & $36.1 \%$ & 82 & $54.7 \%$ & 234 & $46.6 \%$ & \\
\hline & 55 or more & 19 & $12.7 \%$ & 31 & $15.3 \%$ & 28 & $18.7 \%$ & 78 & $15.5 \%$ & \\
\hline & Total & 150 & $100.0 \%$ & 202 & $100.0 \%$ & 150 & $100.0 \%$ & 502 & $100.0 \%$ & \\
\hline \multirow{3}{*}{ Gender } & Male & 143 & $95.3 \%$ & 116 & $58.6 \%$ & 117 & $78.0 \%$ & 376 & $78.0 \%$ & \multirow[t]{2}{*}{$* *$} \\
\hline & Female & 7 & $4.7 \%$ & 82 & $41.4 \%$ & 33 & $22.0 \%$ & 122 & $22.0 \%$ & \\
\hline & Total & 150 & $100.0 \%$ & 198 & $100.0 \%$ & 150 & $100.0 \%$ & 498 & $100.0 \%$ & \\
\hline \multirow{5}{*}{ Marital status } & Married & 120 & $80.0 \%$ & 136 & $75.1 \%$ & 111 & $74.0 \%$ & 367 & $76.3 \%$ & \multirow[t]{4}{*}{$* *$} \\
\hline & Unmarried & 30 & $20.0 \%$ & 38 & $21.0 \%$ & 25 & $16.7 \%$ & 93 & $19.3 \%$ & \\
\hline & Widow & 0 & $0.0 \%$ & 7 & $3.9 \%$ & 11 & $7.3 \%$ & 18 & $3.7 \%$ & \\
\hline & Divorced/separated & 0 & $0.0 \%$ & 0 & $0.0 \%$ & 3 & $2.0 \%$ & 3 & $0.6 \%$ & \\
\hline & Total & 150 & $100.0 \%$ & 181 & $100.0 \%$ & 150 & $100.0 \%$ & 481 & $100.0 \%$ & \\
\hline \multirow{10}{*}{ Education } & Dakhil & 6 & $4.0 \%$ & & & & & & & \multirow[t]{4}{*}{-} \\
\hline & Alim & 30 & $20.1 \%$ & & & & & & & \\
\hline & Fajil & 14 & $9.4 \%$ & & & & & & & \\
\hline & Kamil & 99 & $66.4 \%$ & & & & & & & \\
\hline & Total & 149 & $100.0 \%$ & & & & & & & \\
\hline & No education & & & 52 & $29.5 \%$ & 20 & $13.4 \%$ & 72 & $22.2 \%$ & $* *$ \\
\hline & Primary & & & 41 & $23.3 \%$ & 26 & $17.4 \%$ & 67 & $20.6 \%$ & \\
\hline & $6-10$ & & & 28 & $15.9 \%$ & 21 & $14.1 \%$ & 49 & $15.1 \%$ & \\
\hline & 11 and more & & & 55 & $31.3 \%$ & 82 & $55.0 \%$ & 137 & $42.2 \%$ & \\
\hline & Total & & & 176 & $100.0 \%$ & 149 & $100.0 \%$ & 325 & $100.0 \%$ & \\
\hline \multirow{11}{*}{ Occupation } & Madrasa teacher & 82 & $55.8 \%$ & & & & & & & - \\
\hline & Imam & 33 & $22.4 \%$ & & & & & & & \\
\hline & Muazzin & 4 & $2.7 \%$ & & & & & & & \\
\hline & Others & 28 & $19.0 \%$ & & & & & & & \\
\hline & Total & 147 & $100.0 \%$ & & & & & & & \\
\hline & Service & & & 43 & $24.0 \%$ & 51 & $34.5 \%$ & 94 & $28.7 \%$ & $* *$ \\
\hline & Business & & & 55 & $30.7 \%$ & 42 & $28.4 \%$ & 97 & $29.7 \%$ & \\
\hline & Housewife & & & 49 & $27.4 \%$ & 24 & $16.2 \%$ & 73 & $22.3 \%$ & \\
\hline & Jobless & & & 4 & $2.2 \%$ & 13 & $8.8 \%$ & 17 & $5.2 \%$ & \\
\hline & Others & & & 28 & $15.6 \%$ & 18 & $12.2 \%$ & 46 & $14.1 \%$ & \\
\hline & Total & & & 179 & $100.0 \%$ & 148 & $100.0 \%$ & 327 & $100.0 \%$ & \\
\hline Monthly income & $<10000$ & 51 & $34.7 \%$ & & & & & & & - \\
\hline (in Taka ${ }^{b}$ ) & $10000-20000$ & 84 & $57.1 \%$ & & & & & & & \\
\hline & $>20000$ & 12 & $8.2 \%$ & & & & & & & \\
\hline & Total & 147 & $100.0 \%$ & & & & & & & \\
\hline & $<7000$ & & & 55 & $45.1 \%$ & 60 & $42.6 \%$ & 115 & $43.7 \%$ & n.s. \\
\hline & $7000-15000$ & & & 50 & $41.0 \%$ & 67 & $47.5 \%$ & 117 & $44.5 \%$ & \\
\hline & $>15000$ & & & 17 & $13.9 \%$ & 14 & $9.9 \%$ & 31 & $11.8 \%$ & \\
\hline & Total & & & 122 & $100.0 \%$ & 141 & $100.0 \%$ & 263 & $100.0 \%$ & \\
\hline & Islam & 150 & $100.0 \%$ & & & & & & & \\
\hline & Islam & & & 181 & $95.3 \%$ & 130 & $88.4 \%$ & 311 & $92.3 \%$ & $*$ \\
\hline Religion & Hindu & & & 8 & $4.2 \%$ & 14 & $9.5 \%$ & 22 & $6.5 \%$ & \\
\hline & Buddhism & & & 0 & $0.0 \%$ & 2 & $1.4 \%$ & 2 & $0.6 \%$ & \\
\hline & Christian & & & 0 & $0.0 \%$ & 1 & $0.7 \%$ & 1 & $0.3 \%$ & \\
\hline & Others & & & 1 & $0.5 \%$ & 0 & $0.0 \%$ & 1 & $0.3 \%$ & \\
\hline & Total & & & 190 & $100.0 \%$ & 147 & $100.0 \%$ & 337 & $100.0 \%$ & \\
\hline & 0 & 15 & $10.6 \%$ & 1 & $0.5 \%$ & 67 & $45.0 \%$ & 83 & $16.8 \%$ & $* *$ \\
\hline No of use of & $1-2$ & 27 & $19.0 \%$ & 45 & $22.3 \%$ & 51 & $34.2 \%$ & 123 & $24.9 \%$ & \\
\hline Ayurvedic & $3-4$ & 26 & $18.3 \%$ & 100 & $49.5 \%$ & 23 & $15.4 \%$ & 149 & $30.2 \%$ & \\
\hline $\begin{array}{l}\text { medicine } \\
\text { a year }\end{array}$ & $5-6$ & 68 & $47.9 \%$ & 46 & $22.8 \%$ & 8 & $5.4 \%$ & 122 & $24.7 \%$ & \\
\hline & 6 or more & 6 & $4.2 \%$ & 10 & $5.0 \%$ & 0 & $0.0 \%$ & 16 & $3.2 \%$ & \\
\hline & Total & 142 & $100.0 \%$ & 202 & $100.0 \%$ & 149 & $100.0 \%$ & 493 & $100.0 \%$ & \\
\hline
\end{tabular}




\begin{tabular}{|c|c|c|c|c|c|c|c|c|c|c|c|c|c|}
\hline \multirow{6}{*}{$\begin{array}{l}\text { No of use of } \\
\text { Orthodox } \\
\text { medicine } \\
\text { a year }\end{array}$} & 0 & 2 & \multirow{2}{*}{\multicolumn{2}{|c|}{$\begin{array}{l}1.7 \% \\
14.3 \%\end{array}$}} & 5 & \multirow{2}{*}{\multicolumn{2}{|c|}{$2.6 \%$}} & 3 & \multirow{2}{*}{\multicolumn{2}{|c|}{$2.1 \%$}} & 10 & $2.2 \%$ & \multirow[t]{5}{*}{ ** } \\
\hline & $1-2$ & 17 & & & 94 & & & 4 & & & 115 & $25.3 \%$ & \\
\hline & 3-4 & 42 & \multicolumn{2}{|c|}{$35.3 \%$} & 55 & \multicolumn{2}{|c|}{$28.8 \%$} & 39 & \multicolumn{2}{|c|}{$26.9 \%$} & 136 & $29.9 \%$ & \\
\hline & $5-6$ & 46 & \multicolumn{2}{|c|}{$38.7 \%$} & 29 & \multicolumn{2}{|c|}{$15.2 \%$} & 84 & \multicolumn{2}{|c|}{$57.9 \%$} & 159 & $34.9 \%$ & \\
\hline & 6 or more & 12 & \multicolumn{2}{|c|}{$10.1 \%$} & 8 & \multicolumn{2}{|c|}{$4.2 \%$} & 15 & \multicolumn{2}{|c|}{$10.3 \%$} & 35 & $7.7 \%$ & \\
\hline & Total & 119 & \multicolumn{2}{|c|}{$100.0 \%$} & 191 & \multicolumn{2}{|c|}{$100.0 \%$} & 145 & \multicolumn{2}{|c|}{$100.0 \%$} & 455 & $100.0 \%$ & \\
\hline & & Mean & $10 \%$ & $90 \%$ & Mean & $10 \%$ & $90 \%$ & Mean & $10 \%$ & $90 \%$ & & & \\
\hline \multicolumn{2}{|c|}{ Expenditure of Ayurvedic medicine a year ${ }^{b}$} & 1026.7 & 300 & 2000 & 1152.6 & 200 & 2550 & 376.4 & 000 & 1230 & & & \\
\hline \multicolumn{2}{|c|}{ Expenditure of Orthodox medicine a year ${ }^{b}$} & 3575.8 & 560 & 7000 & 2748.1 & 500 & 5000 & 3707.3 & 560 & 5000 & & & \\
\hline
\end{tabular}

${ }^{a}$ Kruskal-Wallis test for Age,Monthly income,No. of use of Ayurvedic medicine, and No. of use of Orthodox medicine

$\chi 2$-test for gender, Marital status, Education, Occupation, Religion

${ }^{\mathrm{b}} 1 \mathrm{USD}=70$ Taka

${ }^{* *} \mathrm{P}<0.01,{ }^{*} \mathrm{P}<0.05$

Table 2. Perception on Ayurvedic medicine (AM) use in Dhaka, Bangladesh

\begin{tabular}{|c|c|c|c|c|c|c|c|c|c|c|}
\hline & & \multicolumn{6}{|c|}{ Respondents } & & & \multirow{3}{*}{ Test } \\
\hline & & \multicolumn{2}{|c|}{ Religious leaders } & \multicolumn{2}{|c|}{\begin{tabular}{|c|} 
Outpatients of \\
Ayurvedic medicine
\end{tabular}} & \multicolumn{2}{|c|}{$\begin{array}{c}\text { Outpatients of } \\
\text { Orthodox medicine }\end{array}$} & \multicolumn{2}{|c|}{ Total } & \\
\hline & & $\mathrm{n}$ & $\%$ & $\mathrm{n}$ & $\%$ & $\mathrm{n}$ & $\%$ & $\mathrm{n}$ & $\%$ & \\
\hline \multirow[t]{4}{*}{ AM including HM is effective for - } & Only male & 2 & $1.4 \%$ & 2 & $1.0 \%$ & 2 & $1.4 \%$ & 6 & $1.2 \%$ & n.s. \\
\hline & Only female & 4 & $2.7 \%$ & 3 & $1.5 \%$ & 3 & $2.0 \%$ & 10 & $2.1 \%$ & \\
\hline & Both male and female & 140 & $95.9 \%$ & 189 & $97.4 \%$ & 142 & $96.6 \%$ & 471 & $96.7 \%$ & \\
\hline & Total & 146 & $100.0 \%$ & 194 & $100.0 \%$ & 147 & $100.0 \%$ & 487 & $100.0 \%$ & \\
\hline \multirow[t]{5}{*}{ Mode of effect of AM including HM } & Prevention of disease & 90 & $62.1 \%$ & 45 & $23.1 \%$ & 39 & $26.5 \%$ & 174 & $35.7 \%$ & $* *$ \\
\hline & Treatment of diseases & 31 & $21.4 \%$ & 73 & $37.4 \%$ & 20 & $13.6 \%$ & 124 & $25.5 \%$ & \\
\hline & Promotion of health & 18 & $12.4 \%$ & 74 & $37.9 \%$ & 86 & $58.5 \%$ & 178 & $36.6 \%$ & \\
\hline & Others & 6 & $4.1 \%$ & 3 & $1.5 \%$ & 2 & $1.4 \%$ & 11 & $2.3 \%$ & \\
\hline & Total & 145 & $100.0 \%$ & 195 & $100.0 \%$ & 147 & $100.0 \%$ & 487 & $100.0 \%$ & \\
\hline \multirow[t]{6}{*}{ How AM including HM works? } & Eradicate disease & 94 & $64.8 \%$ & 147 & $72.8 \%$ & 46 & $30.9 \%$ & 287 & $57.9 \%$ & $* *$ \\
\hline & Improve body defense & 7 & $4.8 \%$ & 51 & $25.2 \%$ & 57 & $38.3 \%$ & 115 & $23.2 \%$ & \\
\hline & Keep relax & 38 & $26.2 \%$ & 1 & $0.5 \%$ & 37 & $24.8 \%$ & 76 & $15.3 \%$ & \\
\hline & $\begin{array}{l}\text { Remove bad effect of Orthodox } \\
\text { medicine }\end{array}$ & 1 & $0.7 \%$ & 3 & $1.5 \%$ & 3 & $2.0 \%$ & 7 & $1.4 \%$ & \\
\hline & Cures symptoms only & 5 & $3.4 \%$ & 0 & $0.0 \%$ & 6 & $4.0 \%$ & 11 & $2.2 \%$ & \\
\hline & Total & 145 & $100.0 \%$ & 202 & $100.0 \%$ & 149 & $100.0 \%$ & 496 & $100.0 \%$ & \\
\hline
\end{tabular}

$\chi^{2}$-test was used

$*$ " $\mathrm{p}<0.01$

had not decided whether AM involved natural plant formulas, which were healthier than taking drugs given by medical doctors. Moreover, $71.7 \%$ AMOPTs strongly agreed, and $26.3 \%$ agreed that AM involved natural plant formulas healthier than such drugs. On the other hand, $88.0 \%$ OMOPTs agreed on such plant formulas healthier than such drugs. In addition, $80.5 \%$ MRLs agreed, and $10.7 \%$ strongly agreed that people would be more likely to use AM if there were more AM clinics. Furthermore, $77.8 \%$ AMOPTs strongly agreed, and 20.2\% agreed that people would be more likely to use AM if there were more AM clinics. On the other hand, $84.7 \%$ OMOPTs agreed, and $13.3 \%$ had not decided whether people would be more likely to use AM if there were more AM clinics. Moreover, $79.01 \%$ MRLs agreed, and 10.1\% strongly agreed that AM built up the body's own defenses. Furthermore, $76.6 \%$ AMOPTs strongly agreed, and $21.3 \%$ agreed that AM built up the body's own defenses. On the other hand, 66.7\% OMOPTs agreed, and $28.7 \%$ had not decided whether AM built up the body's own defenses. These responses consistently reflected the positive attitudes of AMOPTs toward AM compared to MRLs and OMOPTs. Next we addressed the questions regarding the potential factors influencing such attitudes. $82.6 \%$ MRLs agreed, and $11.4 \%$ strongly agreed that the more knowledge a person had on AM, the more likely he/she would use it. Furthermore, 70.7\% AMOPTs strongly agreed, and $26.8 \%$ agreed on the potential effect of the knowledge. On the other hand, $72.7 \%$ OMOPTs agreed, and $26.0 \%$ had not decided about the potential effect of the knowledge. Moreover, $73.2 \%$ MRLs agreed, and $16.1 \%$ strongly agreed that parents could influence youths to use AM by exposing them to it. Furthermore, $65.3 \%$ AMOPTs strongly agreed, and $30.1 \%$ agreed that parents could influence youths to use AM by exposing them to it. On the other hand, $82.7 \%$ OMOPTs agreed, and $17.3 \%$ had not decided whether parents could influence youths to use AM by exposing them to it. In addition, 73.8\% MRLs agreed, and $15.4 \%$ strongly agreed that people could be influenced to use AM if friends were using it. Furthermore, 65.3\% AMOPTs strongly agreed, and $27.0 \%$ agreed that people could be influenced to use AM if friends were using it. On the other hand, 78.0\% OMOPTs agreed, and $20.0 \%$ had not decided about the potential influence from friends. Moreover, $72.5 \%$ MRLs agreed, and $12.8 \%$ strongly agreed that teachers could influence youths to use AM by exposing them to it. Furthermore, $56.6 \%$ 
Table 3. Satisfaction on Ayurvedic medicine (AM) use in Dhaka, Bangladesh.

\begin{tabular}{|c|c|c|c|c|c|c|c|c|c|c|}
\hline & & \multicolumn{6}{|c|}{ Respondents } & & & \multirow{3}{*}{ Test } \\
\hline & & \multicolumn{2}{|c|}{ Religious leaders } & \multicolumn{2}{|c|}{$\begin{array}{c}\text { Outpatients of } \\
\text { Ayurvedic medicine }\end{array}$} & \multicolumn{2}{|c|}{$\begin{array}{c}\text { Outpatients of } \\
\text { Orthodox medicine }\end{array}$} & \multicolumn{2}{|c|}{ Total } & \\
\hline & & $\mathrm{n}$ & $\%$ & $\mathrm{n}$ & $\%$ & $\mathrm{n}$ & $\%$ & $\mathrm{n}$ & $\%$ & \\
\hline \multirow[t]{3}{*}{ Did you get benefit from AM? } & Yes & 133 & $89.9 \%$ & 200 & $99.5 \%$ & 90 & $60.0 \%$ & 423 & $84.8 \%$ & $* *$ \\
\hline & No & 15 & $10.1 \%$ & 1 & $0.5 \%$ & 60 & $40.0 \%$ & 76 & $15.2 \%$ & \\
\hline & Total & 148 & $100.0 \%$ & 201 & $100.0 \%$ & 150 & $100.0 \%$ & 499 & $100.0 \%$ & \\
\hline \multirow[t]{3}{*}{ Did you get harm from AM? } & Yes & 6 & $4.1 \%$ & 139 & $62.2 \%$ & 0 & $0.0 \%$ & 145 & $29.2 \%$ & $* *$ \\
\hline & No & 142 & $95.9 \%$ & 62 & $30.8 \%$ & 148 & $100.0 \%$ & 352 & $70.8 \%$ & \\
\hline & Total & 148 & $100.0 \%$ & 201 & $100.0 \%$ & 148 & $100.0 \%$ & 497 & $100.0 \%$ & \\
\hline \multirow[t]{4}{*}{ Were you satisfied with AM? } & Very satisfied & 6 & $4.1 \%$ & 65 & $36.7 \%$ & 10 & $8.9 \%$ & 81 & $18.6 \%$ & $* *$ \\
\hline & Satisfied & 137 & $93.2 \%$ & 111 & $62.7 \%$ & 99 & $88.4 \%$ & 347 & $79.6 \%$ & \\
\hline & Dissatisfied & 4 & $2.7 \%$ & 1 & $0.6 \%$ & 3 & $2.7 \%$ & 8 & $1.8 \%$ & \\
\hline & Total & 147 & $100.0 \%$ & 177 & $100.0 \%$ & 112 & $100.0 \%$ & 436 & $100.0 \%$ & \\
\hline \multirow{3}{*}{ Did you recommend AM to others? } & Yes & 138 & $93.9 \%$ & 198 & $99.0 \%$ & 84 & $57.5 \%$ & 420 & $85.2 \%$ & $* *$ \\
\hline & No & 9 & $6.1 \%$ & 2 & $1.0 \%$ & 62 & $42.5 \%$ & 73 & $14.8 \%$ & \\
\hline & Total & 147 & $100.0 \%$ & 200 & $100.0 \%$ & 146 & $100.0 \%$ & 493 & $100.0 \%$ & \\
\hline \multirow[t]{3}{*}{ Does anybody help you using AM? } & Yes & 124 & $88.6 \%$ & 161 & $85.6 \%$ & 15 & $10.3 \%$ & 300 & $63.3 \%$ & $* *$ \\
\hline & No & 16 & $11.4 \%$ & 27 & $14.4 \%$ & 131 & $89.7 \%$ & 174 & $36.7 \%$ & \\
\hline & Total & 140 & $100.0 \%$ & 188 & $100.0 \%$ & 146 & $100.0 \%$ & 474 & $100.0 \%$ & \\
\hline \multirow{4}{*}{$\begin{array}{l}\text { Government should take more } \\
\text { initiatives to promote AM }\end{array}$} & Yes & 105 & $70.9 \%$ & 196 & $100.0 \%$ & 117 & $78.5 \%$ & 418 & $84.8 \%$ & $* *$ \\
\hline & No & 1 & $0.7 \%$ & 0 & $0.0 \%$ & 8 & $5.4 \%$ & 9 & $1.8 \%$ & \\
\hline & $\begin{array}{l}\text { Existing initiatives are } \\
\text { enough }\end{array}$ & 42 & $28.4 \%$ & 0 & $0.0 \%$ & 24 & $16.1 \%$ & 66 & $13.4 \%$ & \\
\hline & Total & 148 & $100.0 \%$ & 196 & $100.0 \%$ & 149 & $100.0 \%$ & 493 & $100.0 \%$ & \\
\hline \multirow{3}{*}{$\begin{array}{l}\text { If treatment cost is same, which } \\
\text { will you choose? }\end{array}$} & $\mathrm{AM}$ & 125 & $87.4 \%$ & 180 & $98.9 \%$ & 9 & $6.4 \%$ & 314 & $67.5 . \%$ & $* *$ \\
\hline & Orthodox medicine & 18 & $12.6 \%$ & 2 & $1.1 \%$ & 131 & $93.6 \%$ & 151 & $32.5 \%$ & \\
\hline & Total & 143 & $100.0 \%$ & 182 & $100.0 \%$ & 140 & $100.0 \%$ & 465 & $100.0 \%$ & \\
\hline
\end{tabular}

$\chi^{2}$-test was used

${ }^{* * *} \mathrm{p}<0.01$

AMOPTs strongly agreed, and $32.7 \%$ agreed on the teachers' influence about the exposure. On the other hand, 73.2\% OMOPTs agreed, and $24.2 \%$ had not decided whether teachers could have such an influence. In addition, $73.6 \%$ MRLs agreed, and $14.9 \%$ strongly agreed that people who believed in the physical, mental, and spiritual aspects of health were more likely to use AM. Furthermore, $46.1 \%$ AMOPTs agreed, and $32.6 \%$ had not decided whether people who believed in them were more likely to use AM. On the other hand, 54.7\% OMOPTs had not decided, and $38.7 \%$ agreed that people who believed in them were more likely to use AM. Moreover, $73.6 \%$ MRLs agreed, and $12.2 \%$ strongly agreed that those who feared the discomfort of treatment from medical doctors were more likely to use AM. Furthermore, 57.1\% AMOPTs had not decided, and $14.6 \%$ agreed that those with such a fear were more likely to use AM. On the other hand, 38.0\% OMOPTs had not decided, and $35.3 \%$ agreed that those with such a fear were more likely to use AM. In addition, $77.0 \%$ MRLs agreed, and $13.5 \%$ strongly agreed that AM was not harmful. Furthermore, 50.0\% AMOPTs had not decided, and $14.6 \%$ agreed that AM was not harmful. On the other hand, $52.0 \%$ OMOPTs agreed, and $44.7 \%$ had not decided whether AM was not harmful. Moreover, 77.4\% MRLs agreed, and 11.6\% strongly agreed that people were motivated to use AM mostly by television, radio, and the mass media. Furthermore, $71.2 \%$ AMOPTs strongly agreed, and $24.7 \%$ agreed with such an effect of the media. On the other hand, $90.7 \%$ OMOPTs agreed with such an effect of the media. These differences were statistically significant.

\section{Discussion}

The results of this study show that the cost of AM seems to be cheaper than the cost of OM. However, with regard to monthly income, there were no statistically significant differences among AMOPTs and OMOPTs. In addition, approximately 50\% AMOPTs were 15-34 years old; on the other hand, the majority of OMOPTs were 35-54 years old. In terms of education, OMOPTs had a higher level of education compared to AMOPTs. From the viewpoint of the perception of AM use in Dhaka, the majority of MRLs believed that AM's mode of effect was prevention of disease. More than one third of AMOPTs believed that it was for disease treatment and health promotion. On the other hand, the majority of OMOPTs believed that AM was for health promotion. Furthermore, whereas the majority of MRLs and AMOPTs believed that AM works via disease eradication, 38.0\% AMOPTs believed that AM works through improving the body's defenses, followed by disease eradication (30.9\%). This demonstrates that there was a large gap in the perception of AM among OMOPTs and the other two groups. The purpose of this study was not only to confirm differences among MRLs, AMOPTs, and OMOPTs but also to confirm that the differences in demographic characteristics were large; this is one of the limitations of this study. However, we think that the difference in the demographic characteristics between the three groups has a meaning.

The results of this study also showed that more than 50\% AMOPTs perceived harm from AM; however, the scores regarding satisfaction were higher than for MRLs and OMOPTs. Moreover, $98.9 \%$ and $87.4 \%$ AMOPTs and MRLs, respectively, would have used AM as the first choice if the cost of treatment was the same. This means that AMOPTs and MRLs trusted the efficacy of AM more. More than 85\% AMOPTs and MRLs had a person who helped him/her use AM; however, only $10.3 \%$ OMOPTs had such a person. This suggested that OMOPTs had more skepticism through not having a person who helped in using AM and were not familiar with using AM. If they had more chance to be 
Table 4. Attitudes of the citizens on Ayurvedic medicine (AM) in Dhaka, Bangladesh.

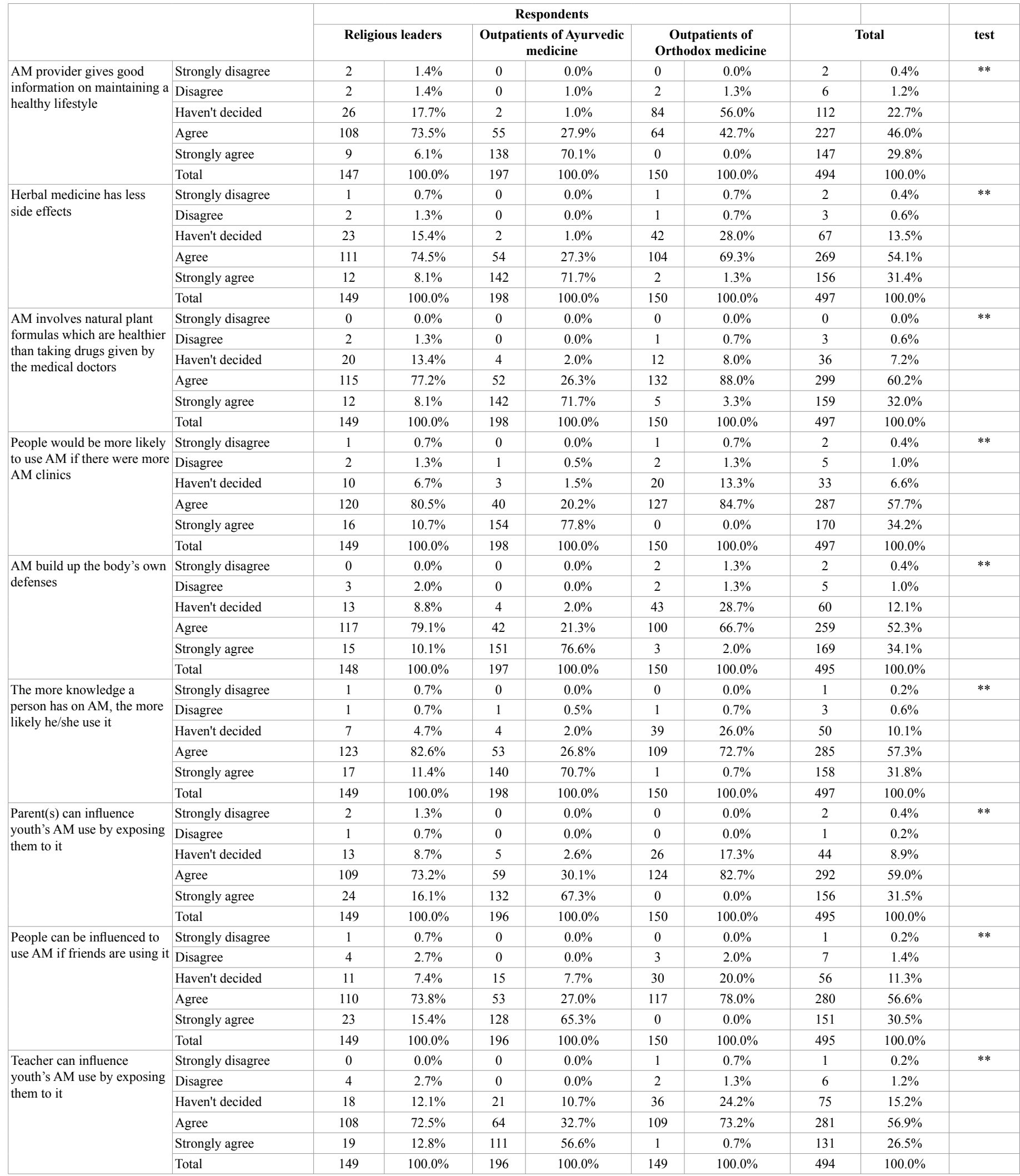




\begin{tabular}{|c|c|c|c|c|c|c|c|c|c|c|}
\hline \multirow{6}{*}{$\begin{array}{l}\text { People who believe in the } \\
\text { physical, mental and spiritual } \\
\text { aspects of health are more } \\
\text { likely to use AM }\end{array}$} & Strongly disagree & 4 & $2.7 \%$ & 0 & $0.0 \%$ & 1 & $0.7 \%$ & 5 & $1.0 \%$ & $* *$ \\
\hline & Disagree & 1 & $0.7 \%$ & 1 & $0.5 \%$ & 5 & $3.3 \%$ & 7 & $1.4 \%$ & \\
\hline & Haven't decided & 12 & $8.1 \%$ & 63 & $32.6 \%$ & 82 & $54.7 \%$ & 157 & $32.0 \%$ & \\
\hline & Agree & 109 & $73.6 \%$ & 89 & $46.1 \%$ & 58 & $38.7 \%$ & 256 & $52.1 \%$ & \\
\hline & Strongly agree & 22 & $14.9 \%$ & 40 & $20.7 \%$ & 4 & $2.7 \%$ & 66 & $13.4 \%$ & \\
\hline & Total & 148 & $100.0 \%$ & 193 & $100.0 \%$ & 150 & $100.0 \%$ & 491 & $100.0 \%$ & \\
\hline \multirow{6}{*}{$\begin{array}{l}\text { Those who fear the } \\
\text { discomfort of treatment from } \\
\text { medical doctors are more } \\
\text { likely to use AM }\end{array}$} & Strongly disagree & 6 & $4.1 \%$ & 11 & $5.6 \%$ & 4 & $2.7 \%$ & 21 & $4.2 \%$ & $* *$ \\
\hline & Disagree & 2 & $1.4 \%$ & 25 & $12.6 \%$ & 30 & $20.0 \%$ & 57 & $11.5 \%$ & \\
\hline & Haven't decided & 13 & $8.8 \%$ & 113 & $57.1 \%$ & 57 & $38.0 \%$ & 183 & $36.9 \%$ & \\
\hline & Agree & 109 & $73.6 \%$ & 29 & $14.6 \%$ & 53 & $35.3 \%$ & 191 & $38.5 \%$ & \\
\hline & Strongly agree & 18 & $12.2 \%$ & 20 & $10.1 \%$ & 6 & $4.0 \%$ & 44 & $8.9 \%$ & \\
\hline & Total & 148 & $100.0 \%$ & 198 & $100.0 \%$ & 150 & $100.0 \%$ & 496 & $100.0 \%$ & \\
\hline \multirow{6}{*}{ AM are not harmful } & Strongly disagree & 0 & $0.0 \%$ & 18 & $9.2 \%$ & 0 & $0.0 \%$ & 18 & $3.6 \%$ & $* *$ \\
\hline & Disagree & 6 & $4.1 \%$ & 28 & $14.3 \%$ & 4 & $2.7 \%$ & 38 & $7.7 \%$ & \\
\hline & Haven't decided & 8 & $5.4 \%$ & 98 & $50.0 \%$ & 67 & $44.7 \%$ & 173 & $35.0 \%$ & \\
\hline & Agree & 114 & $77.0 \%$ & 39 & $19.9 \%$ & 78 & $52.0 \%$ & 231 & $46.8 \%$ & \\
\hline & Strongly agree & 20 & $13.5 \%$ & 13 & $6.6 \%$ & 1 & $0.7 \%$ & 34 & $6.9 \%$ & \\
\hline & Total & 148 & $100.0 \%$ & 196 & $100.0 \%$ & 150 & $100.0 \%$ & 494 & $100.0 \%$ & \\
\hline \multirow{6}{*}{$\begin{array}{l}\text { People are mostly motivated } \\
\text { to use AM by television, } \\
\text { radio and mass media }\end{array}$} & Strongly disagree & 6 & $4.1 \%$ & 0 & $0.0 \%$ & 0 & $0.0 \%$ & 6 & $1.2 \%$ & $* *$ \\
\hline & Disagree & 2 & $1.4 \%$ & 1 & $0.5 \%$ & 0 & $0.0 \%$ & 3 & $0.6 \%$ & \\
\hline & Haven't decided & 8 & $5.5 \%$ & 7 & $3.5 \%$ & 9 & $6.0 \%$ & 24 & $4.9 \%$ & \\
\hline & Agree & 113 & $77.4 \%$ & 49 & $24.7 \%$ & 136 & $90.7 \%$ & 298 & $60.3 \%$ & \\
\hline & Strongly agree & 17 & $11.6 \%$ & 141 & $71.2 \%$ & 5 & $3.3 \%$ & 163 & $33.0 \%$ & \\
\hline & Total & 146 & $100.0 \%$ & 198 & $100.0 \%$ & 150 & $100.0 \%$ & 494 & $100.0 \%$ & \\
\hline
\end{tabular}

$\chi 2$-test was used

"* $\mathrm{p}<0.01$, " $\mathrm{p}<0.05$

familiar with the AM through the help of another person, then, they might use it more.

With regard to attitudes, the results of this study also showed that AMOPTs were the most positive toward AM and that MRLs were also positive; however, OMOPTs were not so positive. In addition, in terms of the influence of parents, friends, and teachers, as a whole, more than $90 \%$ respondents believed that their parents influenced the use of AM, followed by friends $(87.1 \%)$ and teachers $(83.4 \%)$. This also suggests that a person who supports the use of AM is very important in increasing its use. OMOPTs harbored more skepticism than the other two groups. Therefore, to increase the use of AM, appropriate information on its efficacy and safety should be delivered to the general public to avoid skepticism.

In this research, we focused on the difference among MRLs, AMOPTs, and OMOPTs to enhance the usage of AM more. On the other hand, in 2010 we conducted the similar research to confirm the basic perceptions of AM by citizens in Dhaka [23]. The research demonstrated that in terms of effectiveness of AM, the younger generation in Dhaka seemed to be more skeptical to AM than the elder generation in Dhaka, even though the younger generation were more satisfied with AM than the elder generation. Based on the results, with viewpoint of enhancement of usage of AM in Dhaka, we recommended that scientifically sound information on AM should be collected rigorously and brought to the citizens vigorously to remove the skeptical feeling of AM from younger citizen in Dhaka.

In addition, we conducted a study in Japan, and it demonstrated that there was a large gap in the perception of medical terms between citizens and healthcare workers [24-26]. The gaps between the basic recognition of the medical terms by laypeople and that estimated by medical doctors suggest that the possibility that patients cannot recognize much more difficult terms should be considered [24]. In addition, compared with medical doctors, pharmacists tend to overestimate patients' recognition level of medical terms [25]. Furthermore, the level of medical term recognition by patients was much higher when estimated by nurses than when estimated by medical doctors. As members of team care, pharmacists and nurses must consider that patients find technical medical terms to be more difficult than anticipated and that patients are aware of these terms only to a certain extent while receiving healthcare information, such as drug information [26]. Through these results in Japan, we believe that it is critical to address these perception gaps to enhance medical care, which includes AM, in Bangladesh as well.

This study was conducted in Dhaka; however, this type of study should be expanded to other cities in Bangladesh and other countries in Asia with the objective of increasing the use of AM.

We hope that this study will help increase the use of AM, including $\mathrm{HM}$, in not only Bangladesh but also worldwide.

\section{Acknowledgments}

This study was partially supported by the Research Foundation for Oriental Medicine.

\section{Conflicts of interest}

The authors declare that they have no conflicts of interest.

\section{References}

1. WHO (2016) Declaration of Alma-Ata International Conference on Primary Health Care, Alma-Ata, USSR, 6-12 September 1978. http://www.who.int/publications/ almaata_declaration_en.pdf (accessed on October 19, 2016)

2. WHO (2016) WHO Traditional Medicine Strategy 2014-2023, http://www.who.int/ medicines/publications/traditional/trm_strategy14_23/en/ (accessed on October 19, 2016)

3. Moschik EC, Mercado C, Yoshino T, Matsuura K, Watanabe K (2012) Usage and Attitudes of Physicians in Japan Concerning Traditional Japanese Medicine (Kampo Medicine): A Descriptive Evaluation of a Representative Questionnaire-Based Survey. 


\section{Evid Based Complement Alternat Med: 139818. [Crossref]}

4. Government of Japan, Ministry of Health, Labour and Welfare (MHLW) (2016) Annual Health, Labour and Welfare Report 2013-2014. Ministry of Health, Labour and Welfare, Japan. (http://www.mhlw.go.jp/english/wp/wp-hw8/index.html) (accessed on October 19, 2016)

5. Payyappallimana U, Serbulea M (2013) Integration of traditional medicine in the health system of Japan - Policy lessons and challenges. Eur J Integr Med 5: 399-409.

6. Minagawa T, Ishizuka O (2015) Status of urological Kampo medicine: a narrative review and future vision. Int $J$ Urol 22: 254-263. [Crossref]

7. Komiyama S, Takeya C, Takahashi R, Yamamoto Y, Kubushiro K (2015) Feasibility study on the effectiveness of Goreisan-based Kampo therapy for lower abdominal lymphedema after retroperitoneal lymphadenectomy via extraperitoneal approach. $J$ Obstet Gynaecol Res 41: 1449-1456. [Crossref]

8. Ohnishi S, Takeda H (2015) Herbal medicines for the treatment of cancer chemotherapyinduced side effects. Front Pharmacol 6: 14. [Crossref]

9. Nishida S, Eguchi E, Ohira T, Kitamura A, Kato YH, et al. (2014) Effects of a traditional herbal medicines on peripheral blood flow in women experiencing peripheral coldness: a randomized controlled trial. BMC Complement Altern Med 15: 105. [Crossref]

10. Okamoto H, Iyo M, Ueda K, Han C, Hirasaki Y, et al. (2014) Yokukan-san: a review of the evidence for use of this Kampo herbal formula in dementia and psychiatric conditions. Neuropsychiatr Dis Treat 10: 1727-1742. [Crossref]

11. Inoue T, Kulkeaw K, Muennu K, Tanaka Y, Nakanishi Y, et al. (2014) Herbal drug ninjin'yoeito accelerates myelopoiesis but not erythropoiesis in vitro. Genes Cells 19: 432-440. [Crossref]

12. Sakurai M (2011) Perspective: Herbal dangers. Nature 480: S97. [Crossref]

13. Hoban CL, Byard RW, Musgrave IF (2015) A comparison of patterns of spontaneous adverse drug reaction reporting with St. John's Wort and fluoxetine during the period 2000-2013. Clin Exp Pharmacol Physiol 42: 747-751. [Crossref]

14. Ekor M (2014) The growing use of herbal medicines: issues relating to adverse reactions and challenges in monitoring safety. Front Pharmacol 4: 177. [Crossref]

15. Pal S (2015) Impact of hospital delivery on child mortality: An analysis of adolescent mothers in Bangladesh. Soc Sci Med 143: 194-203. [Crossref]
16. Shahabuddin AS, Delvaux T, Abouchadi S, et al. (2015) Utilization of maternal health services among adolescent women in Bangladesh: A scoping review of the literature. Trop Med Int Health 20: 822-829. [Crossref]

17. Harun-Or-Rashid M, Khatun UF, Yoshida Y, Morita S, Chowdhury N, et al. (2009) Iron and iodine deficiencies among under- 2 children, adolescent giMRLs, and pregnan women of Bangladesh: association with common diseases. Nagoya J Med Sci 71: 39-49.

18. Aziz SN, Boyle KJ, Crocker T (2015) Parental decisions, child health and valuation of avoiding arsenic in drinking water in rural Bangladesh. $J$ Water Health 13: 152-167. [Crossref]

19. Edmunds WM, Ahmed KM, Whitehead PG (2015) A review of arsenic and its impacts in groundwater of the Ganges-Brahmaputra-Meghna delta, Bangladesh. Environ Sci Process Impacts 17: 1032-1046. [Crossref]

20. Asadullah MN, Chaudhury N (2011) Poisoning the mind: Arsenic contamination of drinking water wells and children's educational achievement in rural Bangladesh. Econ Educ Rev 30: 873-888.

21. WHO South-East Asia Region (2005) National Policy on Traditional Medicine and Regulation of Herbal Medicines - Report of a WHO Global Survey, 2005.

22. Harun-Or-Rashid M, Yoshida Y, Rashid MA, Nahar S, Sakamoto J (2011) Perceptions of the Muslim religious leaders and their attitudes on herbal medicine in Bangladesh: a cross-sectional study. BMC Res Notes 4: 366. [Crossref]

23. YYoshida Y, Harun-Or-Rashid M, Yoshida Y, Alim MA (2016) Perceptions of Ayurvedic medicine by citizens in Dhaka, Bangladesh. Nagoya J Med Sci 78: 99-107. [Crossref]

24. Yoshida Y, Yoshida Y, Motoyoshi T, Saito M, Saito MA, et al. (2013) Study of perception gaps in pharmaceutical terms and related issues between laypeople and medical practitioners. (in Japanese) Nihon Eiseigaku Zasshi Japanese Journal of Hygiene 68: 126-137.

25. Yoshida Y, Yoshida Y (2014) Patient's recognition level of medical terms as estimated by pharmacists. Environ Health Prev Med 19: 414-421. [Crossref]

26. Yoshida Y, Yoshida Y (2015) Patients' level of medical term recognition as estimated by healthcare workers. Nagoya J Med Sci 77: 123-132. [Crossref]

Copyright: (92016 Yoshida Y. This is an open-access article distributed under the terms of the Creative Commons Attribution License, which permits unrestricted use, distribution, and reproduction in any medium, provided the original author and source are credited. 